\title{
DISCLOSURE
}

\section{HIV DISCLOSURE IN CHILDREN}

\author{
Aneesa Naeem-Sheik, $M B B C h$ \\ Glenda Gray, $M B$ BCh, FCP Paed ( $S A$ ) \\ Perinatal HIV Research Unit, University of the Witwatersrand, fohannesburg
}

With the widespread use of highly active antiretroviral therapy (HAART), the epidemic of paediatric HIV has evolved into a chronic disease of childhood. The difference between this disease and most other chronic diseases of childhood, however, is that it is not only a life-threatening diagnosis but also an extremely stigmatising one, resulting in highly emotionally charged responses to disclosure of such a diagnosis to the patient. The disclosure process is made much more difficult when the person being disclosed to is a child. One of the major difficulties is that one is dealing with many layers of disclosure: disclosure of HIV status to the child; the concomitant disclosure of HIV status of the parent/s and other siblings or other family members; and having to anticipate the child's own disclosure to his/her friends, extended family and community. Approaches to disclosing the diagnosis may vary between parents and between health care providers, but one thing that has been established in many studies world-wide ${ }^{1-4}$ is that the child needs to be informed, many suggesting sooner rather than later during the course of the illness. It has been suggested that disclosure of the diagnosis to the child is an integral part of providing comprehensive medical care to a child infected by HIV ${ }^{5}$ and may impact positively on adherence to medication. During adolescence, disclosure of the diagnosis may also aid in preventing high-risk behaviour, thereby curbing spread of the disease. Disclosure of HIV to a child should be seen as an ongoing process that may last several years depending on the cognitive development of the child. Health care providers who deal with HIV infection in children need to develop a plan that will enable them to support parents in disclosure.

FACTORS INFLUENCING THE DISCLOSURE OF HIV STATUS BY PARENTS TO THEIR CHILDREN

- Parents feel responsible for shielding their children from potentially harmful knowledge. ${ }^{6}$

- Discrimination against infected persons by peers, at schools, in day-care centres and in the community as a whole.

- Parents who are coping with their children's illness must at the same time cope with their own illness, declining health and imminent death.

- Parental feelings of guilt, blame and responsibility for their children's HIV infection.?

- Fear that the diagnosis will negatively affect the child's will to live. ${ }^{8}$

- Fear of anger from the child related to perinatal transmission. $^{8}$

- Fear of inadvertent disclosure by the child to the broader community.

\section{ADVANTAGES OF DISCLOSING TO A CHILD}

Greater ability to cope and provide support to each other, especially as the disease progresses.

- Increased intimacy between parent and child once disclosure has occurred, which often results in stronger family ties.
Parents feel relieved of the burden of keeping a secret, and less anxious about medical visits and the possibility of accidental disclosure. ${ }^{1,2}$

Forms an essential part of good health.

- Communicates respect for the child.

Reflects a child's individual rights.

Empowers the child to participate in health care.

Enables choices and self-protection. ${ }^{5}$

Increases hope. 6,9

\section{WHEN TO WITHHOLD/DELAY DISCLOSURE}

Very young child (usually under the age of 5 years) or a child with developmental delay (as defined by $10<70$ ). ${ }^{2}$

- Children with severe emotional disturbances.

These children should have their situations assessed periodically should their circumstances change.

\section{FACTORS ASSOCIATED WITH EARLY DISCLOSURE IN} HIV-INFECTED CHILDREN

Lester et $a l^{6}{ }^{6}$ reported their findings in a cross-sectional study of 51 HIV-infected children. They concluded that the following factors play an important role in determining whether disclosure to a child takes place earlier rather than later: 
A child with a higher I0. Higher IOs relate to the child's developmental readiness to understand the complex and changing nature of HIV diagnosis and prognosis.

- Urban family residence. Although families from both rural and urban settings expressed fear about negative reactions from the community, it was found that the more negative attitudes were prevalent in communities that lacked HIV/AIDS education and services. Disclosure to children in these communities was therefore found to be delayed.

- Families with higher expressiveness. Assessment of family communication style is important in determining whether a child should be disclosed to earlier rather than later.

They also found that at the time of study initiation, subjects who had already been disclosed to had:

- Higher mean ages (10.5 years).

- Increased major life events within the family in the preceding year.

\section{PROCESS OF DISCLOSURE}

Disclosure is a process that should take place over a period of time. It requires ongoing and effective communication within families. It requires that health professionals respect family needs, wishes and expectations as well as community norms and pressures.

Disclosure must take into account:

- The needs of the child AND the needs of the parent/family. Pushing the process before the family is ready may disrupt the therapeutic alliance and have a negative impact on the ongoing care of the child. ${ }^{9}$

Evolving developmental and psychological status of the child.

- Special adherence challenges for children.

- The evolving nature of the illness.

- Time for discussion with parents during each visit and time to prepare them for difficult questions that may come later. $^{9}$

- The need to decrease social isolation - this can be achieved by encouraging discussions between parents and other regivers during clinic visits.

\section{THE CHILD}

- Information appropriate to the age and development (including emotional development) of the child in response to questions, especially with regard to clinical visits, drawing of blood, and medication.

- Parents should never knowingly tell untruths, as this will decrease the trust between parent and child.

- Ascertain what the child knows or suspects about his/her diagnosis.

Determine the child's state of mind - depressed, worried, anxious? ${ }^{5}$
Determine whether the child is sexually active or not.

Children who ask direct questions are ready to hear about their diagnosis and will seek that information elsewhere if the parents and health care providers are not forthcoming in providing it. ${ }^{7}$

\section{THE PARENT}

Factors to consider:5,9

Parental HIV status.

Disease stage.

Who is the child's primary caregiver?

Who is emotionally closest to the child?

Is the parent living at home?

Communication style within the family.

- Impact of the disease on other family members.

- Fears, concerns and attitudes with regard to disclosure.

The book by Mary Tasker, How Can I Tell You?,10 outlines the four common phases of disclosure by a parent, namely:

- Secrecy/privacy phase. This occurs immediately after learning the child's diagnosis. The diagnosis is kept secret or private from anyone outside the medical centre.

Exploratory phase. This occurs later, when the parent is willing to disclose the diagnosis to a close friend or family member. The parent will often also offer the child a plausible though not entirely thorough explanation for the numerous medical visits

Readiness phase. This occurs when the parent begins to disclose to a larger network and starts entertaining the idea of fully disclosing to the child.

Disclosure phase. This is when full disclosure to the child occurs. Lee et al. ${ }^{11}$ found that disclosure is best done over a period of time at different phases of the child's life and involving a multidisciplinary approach that includes the parents/caregivers.

Parents can be helped through these phases taking into account what has been ascertained about the child, the parent, the family and the community as a whole.

\section{REACTIONS TO DISCLOSURE}

\section{DENIAL}

Children may deny having the disease, or may claim that they are cured of the disease. This becomes a problem when the child starts to refuse medical care, misses appointments or sabotages treatment. These children may need the intervention of a psychologist to help them cope with coming to terms with the diagnosis. Support groups with similar children may be helpful.

\section{SADNESS AND DEPRESSION}

This is a more common response but is usually short-lived. The child requires reassurance and assistance in exploring and coming to terms with his or her feelings, fears and anxieties. Should a more chronic period of depression set in, a professional should be consulted to help deal with the depression.

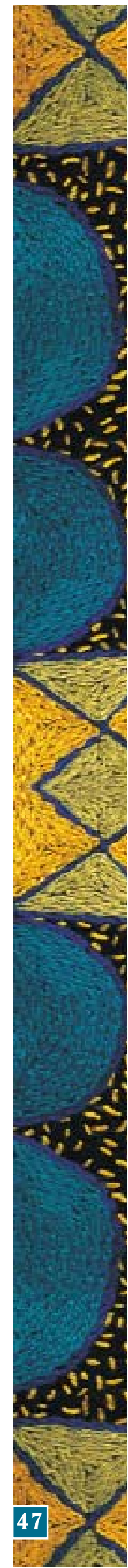




\section{SUICIDE}

This is extremely rare, and should there be an expression of suicidal ideation a mental health professional needs to be consulted.

\section{GOOD WAYS TO DISCLOSE}

Disclosure should occur between the primary caregiver, parent and child with or without health care providers.

- It should be:

- driven by the child's agenda

- planned

- private

- loving and reassuring

- unhurried.

\section{WAYS NOT TO DISCLOSE}

Disclosure should not be done:

accidentally

in the heat of anger

AFTER the child has figured it out for him/herself

when the child puts a provider 'on the spot'.

\section{WHAT TO SAY}

'You know you have been coming to this clinic for a long time? You come because you have a long-standing illness/infection that requires regular check-ups and medication. The medication you take helps the illness, and helps to keep you well.'

When the parents and health care provider are sure that the child understands these concepts, the disclosure can go a bit further. 'That illness or infection we spoke about - well, it is caused by a virus/germ. Do you know what a virus/germ is? The medication that you take to keep you well works by killing this virus/germ.' After a period of time, the parents or health care provider may then name the virus.

The parent should practise the disclosure with the health care provider. They should also explore answers to some of the difficult questions, like 'How did I get it?' or 'How did you get it?'

\section{CONCLUSIONS}

We believe that every health care provider should develop a plan with the HIV-infected child's parents or guardians that will outline the process of HIV disclosure. Disclosure is a process that should occur over a period of time, and should occur before the child discovers his or her own diagnosis. Role-playing with the child's parents or guardians will enable them to prepare answers for difficult questions and facilitate support for adverse outcomes following disclosure.

\section{REFERENCES}

1. Lipson M. Disclosure of diagnosis to children with human immunodeficiency virus or acquired immune deficiency syndrome. J Dev Behav Pediatr 1994; 15(3): 61-65.
Recommendations by the American Academy of Pediatrics with regard to disclosure to children and adolescents

Parents/guardians of an HIV-infected child need to be counselled by a knowledgeable health care professional about disclosure to the child. This counselling may need to be repeated throughout the course of the child's illness.

- Disclosure needs to be individualised to include the child's cognitive ability, developmental stage, clinical status and social circumstances.

- In general, younger children, if symptomatic with illness, are more interested in learning what will happen to them in the more immediate future. They do not need to be informed of their diagnosis, but the illness should be discussed with them. If children are informed of their diagnosis, effort should be directed towards eliciting and addressing their fears and misconceptions.

- The American Academy of Pediatrics strongly encourages disclosure of HIV infection status to school-age children. The process for disclosure should be discussed and planned with the parents and may require a number of visits to assess the child's knowledge and coping capacity. Considerable effort will need to be directed to facilitate coping with the illness. Symptomatic children, particularly those requiring hospitalisation, should be informed of their HIV status. The likelihood of children inadvertently learning about their HIV status in a hospital setting is high. Disclosure should optimally be conducted in a controlled situation and should include parents and knowledgeable professionals.

- Adolescents should know their HIV status. They should be fully informed to appreciate consequences for many aspects of their health, including sexual behaviour.

- Adolescents also should be informed of their HIV status to make appropriate decisions about treatment and participation in clinical treatment trials. Physicians should also encourage adolescents to involve their parents in their care.

2. Lipson M. Disclosure within families. AIDS Clinical Care 1993; 5: 43-44.

3. Claflin CJ, Barbarin OA. Does telling less protect more? Relationships among age, information disclosure, and what children with cancer see and feel. J Ped Psych 1991; 16: 169-191.

4. Funck-Bretano I, Costagiola D, Seibel N, et al. Patterns of disclosure and perceptions of the human immunodeficiency virus in infected elementary school age children. Arch Pediatr Adolesc Med 1997; 151: 978-985.

5. MTCT+ Training (2005) - Johannesburg (SA). Paediatric Disclosure: Talking to Children about HIV.

6. Lester $\mathrm{P}$, Chesney $\mathrm{M}$, Cooke $\mathrm{M}$, et al. When the time comes to talk about HIV: Factors associated with diagnostic disclosure in HIV-infected children. $J$ Acquir Immune Defic Syndr 2002; 31(3): 309-317.

7. FXB Worldwide - A Resource for Paediatric HIV/AIDS Clinicians. Disclosing the HIV Diagnosis to Infected Children. Oct 1997 (4).

8. American Academy of Pediatrics (Committee on Paediatric AIDS). Disclosure of illness Status to children and Adolescents with HIV Infection. Pediatrics 1999; 103: 164-165

9. Tepper V, Bachanas P. PACTG Training - Johannesburg, SA (2004). Management of Paediatric and Perinatal HIV Infection in the Era of Antiretroviral Therapy.

10. Tasker M. How Can I Tell You? Bethesda, Md: Association for the Care of Children's Health, 1992

11 Lee CL, Johann-Liang R. Disclosure of the diagnosis of HIV/AIDS to children born of HIV-infected mothers. AIDS Patient Care STDs 1999; 13 (Jan): 41-45. 